\title{
Antibacterial activity of wood distillate from residual virgin chestnut biomass
}

\author{
Francesco Misuri $^{1} \cdot$ Laura Marri $^{1}$ (D)
}

Received: 3 August 2020 / Accepted: 8 October 2020 / Published online: 24 October 2020

(c) The Author(s) 2020

\begin{abstract}
The antibacterial properties of a wood distillate obtained from residual virgin chestnut biomass were investigated by means of quantitative MIC (minimum inhibitory concentration) test and a whole-cell assay that specifically responds to different classes of antimicrobials on the basis of the mode of action. Results indicate that wood distillate is active against grampositive and gram-negative bacteria related to human and/or fish diseases with a mechanism, which could mainly affect wall components and plasma membrane of the bacterial cells. These findings highlight the possible sustainable use of chestnut residues as a source of bioactive natural compounds with antibacterial properties.
\end{abstract}

\section{Introduction}

Wood distillate (WD), also known as pyroligneous acid or wood vinegar, is a heterogeneous solution obtained from the thermochemical conversion of the constituents of the plant biomass, mainly the polysaccharides, cellulose and hemicelluloses, and the non-linear aromatic polymer lignin (Mathew and Zakaria 2015). WD is a yellowish brown or dark brown liquid with acidic $\mathrm{pH}$ and a chemical composition highly variable depending on the heating rate, temperature, and nature of the raw material used in pyrolysis. It usually comprises a complex mixture of volatile organic compounds such as organic acids, aldehydes, phenols, alcohols, ketones, pyranfuran derivatives, and polyphenolic compounds (Hou et al. 2018; Suresh et al. 2019).

WD finds application in diverse areas, as antioxidant, antimicrobial, antiinflammatory, plant growth stimulator, coagulant for natural rubber, and termiticidal and pesticidal agent (Grewal et al. 2018). Moreover, it was found effective against a wide range of organisms, eukaryotes and prokaryotes, and a clear correlation between WD antimicrobial properties and its chemical composition was documented (Hou et al. 2018; Suresh et al. 2019). The main aim of this study was to investigate the antibacterial activity of WD

Laura Marri

laura.marri@unisi.it

1 Department of Life Sciences, University of Siena, via A. Moro 2, 53100 Siena, Italy obtained by native chestnut biomass and get indications of its possible cellular targets.

\section{Materials and methods}

The chestnut (Castanea sativa Mill.) WD object of the study is produced in Val di Chiana (Arezzo, Italy) by Esperia s.r.l. (RM Group Energy Solutions), and distributed by BioDea $\odot$. The data sheet of the product reports that it is obtained from virgin residual wood biomass in the countercurrent of steam from a pyrogasification reactor with the same physiological water and extracted at different temperature gradients, with a maximum output from the reactor of $75^{\circ} \mathrm{C}$. The resulting WD is composed of more than 300 organic substances and it is rich in tannins $(0.13 \%)$ and polyphenols (23-26 g/kg) [https://www.biodea.bio/website/ wp-content/uploads/2020/05/Biodea-Wood-Distillate.pdf]. The sample object of this study (product batch: 1-05/2019, expiry date: 60 months) was kindly provided by S. Loppi (Department of Life Sciences, University of Siena). Minimum inhibitory concentration (MIC) of WD was evaluated against 14 reference strains representative of Gram-positive and Gram-negative bacterial species, including human and/ or fish pathogens obtained by the American Type Culture Collection (ATCC) and Deutsche Sammlung von Mikroorganismen und Zellkulturen (DSMZ): Staphylococcus aureus ATCC 25923, Enterococcus faecalis ATCC 29212, Bacillus subtilis ATCC 6633, Bacillus cereus ATCC 11778 , Micrococcus luteus ATCC 4698, Escherichia coli ATCC 
23739, Salmonella typhimurium ATCC 23853, Enterobacter cloacae ATCC 13047, Proteus vulgaris ATCC 6380, Pseudomonas aeruginosa ATCC 17853, Vagococcus salmoninarum DSM 6633, Lactococcus garviae DSM 6783, Listonella anguillarum DSM 11323, and Aeromonas salmonicida DSM 46293. Luria-Bertani (LB) [1\% Bacto tryptone, $0.5 \%$ Bacto yeast extract, $0.5 \% \mathrm{NaCl}, \mathrm{pH} 7.2]$ was the medium used for the routine cultivation and maintenance of bacteria, while Mueller Hinton (MH) broth (Oxoid, Thermo Fisher Scientific, Basingstoke, UK) was used for antibacterial quantitative assay.

MICs were carried out with a broth microdilution method (NCCLS 2001). Twofold serial dilutions of WD in MH broth were prepared directly in 96-well microdilution plate (the test was performed in duplicate for each strain on the same plate). The bacterial inoculum was added to give a final concentration of $\sim 5 \times 10^{5}$ colony-forming unit $(\mathrm{CFU}) / \mathrm{mL}$ in each well, with the exception of that intended for use as a negative control. The plate was then covered with a sterile sealer and incubated for $24-48 \mathrm{~h}$ at $30{ }^{\circ} \mathrm{C}$. MIC was determined as the lowest concentration of the extract inhibiting the visual growth of the test cultures. For all strains two independent experiments were carried out. Minimum bactericidal concentration (MBC), namely the minimum concentration needed to cause a 3-logarithmic decrease (99.9\% killing) in the size of the standard inoculum was also determined for all ATCC strains. The entire broth dilutions that had inhibited growth of bacteria (i.e., those at or above the MIC) were spread onto LB-agar ( $1.6 \mathrm{~g} / \mathrm{L})$ plate and incubated for 24 to $48 \mathrm{~h}$ in order to determine the number of CFUs.

A "blue halo assay" was performed in order to detect a possible mechanism of action of WD (Bianchi and Baneyx 1999). Lysogenic strains of E. coli K-12 carrying singlecopy gene fusions between the lac $Z$ reporter gene and promoters induced by cold shock ( $\operatorname{csp} \mathrm{A})$, cytoplasmic stress $(i b p)$, or protein misfolding in the cell envelope $(\mathrm{P} 3 r p o \mathrm{H})$ were used in order to categorize known antibacterial agents on the basis of their cellular targets (Bianchi and Baneyx 1999). E. coli strains ADA110 $\lambda \phi$ [ibp::lacZ], ADA $310 \lambda \phi$ [cspA::lacZ], and ADA $410 \lambda \phi$ [P3rpoH::lacZ] were kindly provided by F. Baneyx (Dept. of Chemical Engineering \& Bioengineering, University of Washington, US). The assay was carried out according to the procedure reported by Bianchi and Baneyx (1999). In brief, LB top agar (0.7\% agar) supplemented with ADA110, ADA 310, and ADA 410 cells was poured over LB agar plates $(\varnothing 5 \mathrm{~cm})$ spread with $10 \mu \mathrm{l}$ of $50 \mathrm{mg} / \mathrm{ml}$ 5-bromo-4-chloro-3-indolyl $\beta$-Dgalactopyranoside (X-Gal; Sigma-Aldrich, Darmstadt, Germany). Antibiotic disks (Whatman, $\varnothing 6 \mathrm{~mm}$ ) were impregnated with $10 \mu \mathrm{l}$ of WD (1:100 in $\left.10 \mathrm{mM} \mathrm{MgSO}_{4}\right)$ and then placed on the agar surface using sterile forceps. The plates were incubated overnight at $30^{\circ} \mathrm{C}$ or $37{ }^{\circ} \mathrm{C}$. Controls including antibiotics streptomycin sulfate, carbenicillin, and polymyxin B sulfate (all purchased from Sigma-Aldrich) were also carried out as previously described (Bianchi and Baneyx 1999).

\section{Results and discussion}

For each strain, MICs, collected from two independent experiments, were completely superimposable to each other. All results obtained after 24 and $48 \mathrm{~h}$ of growth at $30^{\circ} \mathrm{C}$ are presented in Table 1. After $24 \mathrm{~h}$ of growth, gram-positive and gram-negative bacteria were inhibited by WD with MIC ranging from $0.39 \%(\mathrm{v} / \mathrm{v})$ to $1.56 \%$; after prolonged incubation, \% MIC values ranged from 0.78 to 1.56 , with the latter value being shared by the majority of the tested strains (six gram-positive and four gram-negative). MBCs resulted comparable (M. luteus, B. cereus, and B. subtilis) or only varied by one dilution factor (all remaining strains); the MBC/MIC ratio $(\leq 2)$ showed that WD had bactericidal activity against all ATCC strains tested.

"Blue halo assay" results indicated that, at sublethal concentrations, WD induced both the P3rpoH::lacZ and $i b p$ : : lac Z fusions (Fig. 1). This induction profile was also reported for the membrane damaging peptide polymyxin B (Bianchi and Baneyx 1999). On that basis, WD likely causes the perturbation of cell wall components and plasma membrane of gram-negative and gram-positive bacteria. The observation is in agreement with the proposed model of interaction with bacterial structures of polyphenols (Papuc

Table 1 MIC values of WD against reference strains after 24 and $48 \mathrm{~h}$ of incubation

\begin{tabular}{lll}
\hline Microorganism & \%MIC24 & \%MIC48 \\
\hline Gram-positive & & \\
$\quad$ Staphylococcus aureus ATCC 25923 & 1.56 & 1.56 \\
Enterococcus faecalis ATCC 29212 & 1.56 & 1.56 \\
Micrococcus luteus ATCC 4698 & 0.39 & 0.78 \\
Bacillus subtilis ATCC 6633 & 1.56 & 1.56 \\
Bacillus cereus ATCC 11778 & 1.56 & 1.56 \\
Vagococcus salmoninarum DSM 6633 & 1.56 & 1.56 \\
Lactococcus garviae DSM 6783 & 0.78 & 1.56 \\
Gram-negative & & \\
Escherichia coli ATCC 23739 & 0.78 & 1.56 \\
Pseudomonas aeruginosa ATCC 17853 & 0.78 & 1.56 \\
Salmonella typhimurium ATCC 23853 & 1.56 & 1.56 \\
Enterobacter cloacae ATCC 13047 & 0.78 & 1.56 \\
Proteus vulgaris ATCC 6380 & 0.78 & 1.56 \\
Aeromonas salmonicida DSM 46293 & 0.78 & 0.78 \\
Listonella anguillarum DSM 11323 & 0.39 & 0.78 \\
\hline
\end{tabular}




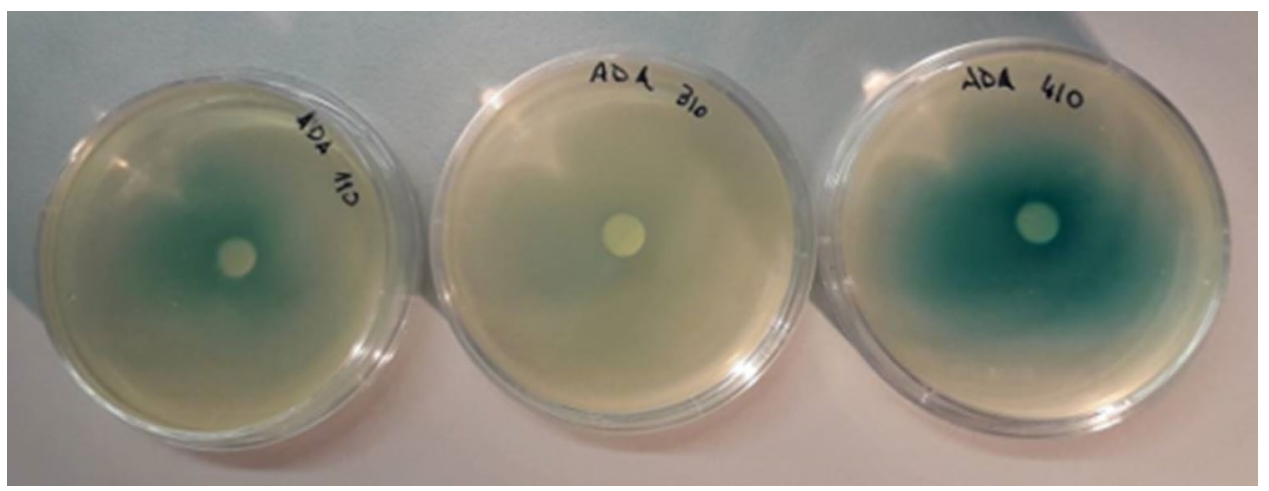

Fig. 1 Example of differential induction of stress-induced promoters by sublethal concentration of WD. From left to right, top agar was supplemented with genetically modified Escherichia coli strains ADA110 $\lambda \phi$ [ibp::lacZ], ADA $310 \lambda \phi$ [cspA::lacZ], and ADA 410

et al. 2017), which are present, at a relatively high concentration, in the WD object of this study.

\section{Conclusion}

WD from chestnut biomass was found to have a spectrum of activity including both gram-positive and gram-negative reference strains belonging to bacterial species representative of human and/or fish pathogens. The current antibacterial therapy is being increasingly threatened by the emergence and spread of multidrug resistant bacteria. The present observations provide a basis for further investigations into the antibacterial properties of WD in order to evaluate its possible development into useful sterile products for medical, and livestock breeding applications as in aquacultures.

Funding Open access funding provided by Università degli Studi di Siena within the CRUI-CARE Agreement. This work was supported by funding from the University of Siena (project number 2264-2019-BCPSR2019_001) to LM.

\section{Compliance with ethical standards}

Conflict of interest The authors declare that they have no conflict of interest.

Open Access This article is licensed under a Creative Commons Attribution 4.0 International License, which permits use, sharing, adaptation, distribution and reproduction in any medium or format, as long as you give appropriate credit to the original author(s) and the source, provide a link to the Creative Commons licence, and indicate if changes were made. The images or other third party material in this article are included in the article's Creative Commons licence, unless indicated $\lambda \phi[\mathrm{P} 3$ rpoH::lacZ]. Antibiotic disks containing WD framed by a blue ring due to the cleavage of $\mathrm{X}$-Gal by $\beta$-galactosidase show the response of a specific lysogenic strain (Bianchi and Baneyx 1999)

otherwise in a credit line to the material. If material is not included in the article's Creative Commons licence and your intended use is not permitted by statutory regulation or exceeds the permitted use, you will need to obtain permission directly from the copyright holder. To view a copy of this licence, visit http://creativecommons.org/licenses/by/4.0/.

\section{Reference lists}

Bianchi AA, Baneyx F (1999) Stress responses as a tool to detect and characterize the mode of action of antibacterial agents. Appl Environ Microbiol 65:5023-5027

Grewal A, Abbey L, Gunupuru LR (2018) Production, prospects and potential application of pyroligneous acid in agriculture. $\mathbf{J}$ Anal Appl Pyrolysis 135:152-159

Hou X, Qiu L, Luo S, Kang K, Zhu M, Yao Y (2018) Chemical constituents and antimicrobial activity of wood vinegars at different pyrolysis temperature ranges obtained from Eucommia ulmoides Olivers branches. RSC Adv 8:40941-40949

Mathew S, Zakaria ZA (2015) Pyroligneous acid-the smoky acidic liquid from plant biomass. Appl Microbiol Biotechnol 99:611-622

NCCLS (2001) Development of in vitro susceptibility testing criteria and quality controls parameters; approved guideline, 2nd edn. M23-A2. National Committee for Clinical Laboratory Standards, Wayne

Papuc C, Goran GV, Predescu CN, Nicorescu V, Stefan G (2017) Plant polyphenols as antioxidant and antibacterial agents for shelflife extension of meat and meat products: classification, structures, sources, and action mechanisms. Compr Rev Food Sci F 16:1243-1268

Suresh G, Pakdel H, Rouissi T, Brar SK, Fliss I, Roy C (2019) In vitro evaluation of antimicrobial efficacy of pyroligneous acid from softwood mixture. Biotechnol Res Innov 3:47-53

Publisher's Note Springer Nature remains neutral with regard to jurisdictional claims in published maps and institutional affiliations. 